\title{
DESIGN OF A CURVED 414M LONG CONTINUOUS CONCRETE RAILWAY BRIDGE TO RESIST EARTHQUAKE MOTIONS
}

\author{
R.D. Jury ${ }^{*}$, J.P. Hollings ${ }^{*}$ and T.J. Catley*
}

\begin{abstract}
SUMMARY
Recent upgrading and realignment work on the Main Trunk Rail route between ohakune and Horopito has required the replacement of the previous Hapuawhenua viaduct with a $414 \mathrm{~m}$ long bridge on a $420 \mathrm{~m}$ curve and at a 1.57\% gradient. Expected seismic performance has been given particular consideration in the design of the new bridge and the designers believe that the structural arrangement chosen has led to an economic solution providing excellent and predictable seismic behaviour even for very large earthquakes.
\end{abstract}

Editors Note: This paper was first published in the Proceedings of the 1988 Pacific Concrete Conference and is reprinted with the permission of the Cement and Concrete Association of New Zealand and the New Zealand Concrete Society.

\section{INTRODUCTION}

A project to electrify a portion of the Main Trunk rail route in the North Island of New Zealand has only recently been completed. In conjunction with this project $7.5 \mathrm{~km}$ of track between ohakune and Horopito (Central North Island) have been realigned to remove the existing tight curves and steep gradients thus improving traffic speed and load carrying capacity. This has required the replacement of the existing Hapuawhenua viaduct with a new crossing traversing the Hapuawhenua stream.

Both the location of the site, close to the boundary of Zones $A$ and $B$ of the New Zealand loadings code [7] and the economic importance of this rail link required a concept which could be expected to provide excellent seismic performance.

The site requirements were for a crossing of approximately $400 \mathrm{~m}$ in length, on a $420 \mathrm{~m}$ radius curve and on a $1.57 \%$ gradient.

The bridge was designed during 1984; the tender for construction was let to Fletcher construction Co Ltd in early 1985 and construction was completed in March 1987.

\section{OPTIONS CONSIDERED}

Early studies indicated that a large culvert crossing which would require fill to a depth of $45 \mathrm{~m}$ on centre line was neither cost competitive with a bridge crossing, nor, due to the scale of earthworks required, compatible with the environmentally sensitive site. One of the difficulties with the approach embankment

* Beca Carter Hollings \& Ferner Ltd Wellington associated with a culvert crossing was that the toe would run to the bottom of the valley and part way up the opposite side. In addition ground cross fall and unsuitable surface materials of soil would have required removal of 2 to $5 \mathrm{~m}$ to waste prior to the commencement of the embankment construction.

Once the decision to provide a bridge was made there were two basic alternatives to consider:

1. a bridge of approximately $400 \mathrm{~m}$ length which would span the valley without the need for substantial approach embankment fills;

and

2. a compromise solution of a minimum length bridge (of approximately $200 \mathrm{~m}$ length) with approach embankment fills of up to $30 \mathrm{~m}$ centreline depth.

Numerous bridge deck alternatives were considered. These included:

1. Universal beam sections spanning $10 \mathrm{~m}$, welded plate girders spanning $20 \mathrm{~m}$, and $40 \mathrm{~m}$ span galvanised steel trusses.

2. Continuous reinforced concrete spanning $20 \mathrm{~m}$.

3. Continuous post tensioned concrete with 20,40 and $60 \mathrm{~m}$ spans cast-in-situ or incrementally launched;

and

4. Simply supported precast concrete units with a composite concrete deck. 
Ballasted and non-ballasted rail support options were evaluated for each of the above.

For deck support steel lattice piers (for the steel alternatives) and reinforced concrete piers of various dimensions were investigated as were two foundation types of either reinforced concrete pad footings or bored cast-in-situ reinforced concrete piles. The 2 to $5 \mathrm{~m}$ depth of surface materials required to be removed for surface footings together with their physical size however made it immediately apparent that they were an uneconomic solution.

For the compromise solution four embankment options were investigated:

1. Through-tied concrete walls backfilled with the locally available siltstone.

2. Stepped (necessary because of the height of fill) reinforced earth using scoria backfill.

3. Siltstone (available adjacent to the site) embankment with side slopes of $2: 1$ for seismic stability, and

4. Scoria (imported from Ohakune) embankment with side slopes of 1.5:1 for seismic stability.

Preliminary design and costings were carried out on each of the alternatives described above and the decision was made to proceed with the unballasted, $414 \mathrm{~m}$ long, $20 \mathrm{~m}$ span, continuous post-tensioned concrete deck on reinforced concrete piers and piles.

\section{GENERAL ARRANGEMENT}

The general arrangement of the bridge as finally constructed is shown in Fig. 1. The bridge comprises nineteen spans of $20 \mathrm{~m}$ and two $17 \mathrm{~m}$ end spans.

The deck is a solid concrete section of uniform cross-section except for the spans adjacent the anchor pier which are hollow and haunched. The deck profile both for the typical and haunched spans is also shown in Fig. 2. Deck prestressing was carried out using the VSL prestressing system with 10 $17 / 12.5 \mathrm{~mm}$ strand cables used in the typical spans.

The deck is continuous and built into the majority of the piers to ensure the structural integrity of the bridge during severe earthquakes. Temperature, creep and shrinkage effects are however significant in a deck of this length and large stresses in the superstructure result from the restraint provided by the shorter piers at each end of the bridge. In addition the wide variation in the stiffness of the piers which range in height from $3.5 \mathrm{~m}$ to $47.6 \mathrm{~m}$ has the potential to adversely affect the distribution of stresses in the bridge under longitudinal loading and ductility in the piers during severe earthquake shaking.

To mitigate these effects the following details were introduced:
1. A stiff anchor pier, thus allowing the longitudinal stiffness of the other piers to be reduced to a minimum.

2. Fully sliding bearings at the top of piers 2 and 21 ,

3. A pin between the deck and the top of piers 3, 4, 18, 19 and 20,

4. Longitudinally sliding and transversely guided abutments; and

5. A constant section size for the upper $30 \mathrm{~m}$ of each pier, with the pier hinges under longitudinal earthquake forces forced to form at the extremities of this section. Hinging the thickened portion of piers $11,12,13,14$, and 15 was prevented using capacity design techniques.

It was originally intended to position the anchor pier at the south end of the bridge in pier position 2 (Fig. 1). However preliminary analyses with the anchor pier in this location indicated that the anchor pier and the pier at position 8 were interacting under longitudinal train braking and earthquake loads. This resulted in large transverse effects in the deck between these two piers especially adjacent the anchor pier.

It was also apparent that under thermal and creep and shrinkage effects significant shears were generated in both the anchor pier and the stiffer piers near the Auckland (northern) abutment leading to large tensions in the deck. The above factors led to a shift of the anchor pier to its final location at pier portion 8 . The centre of the stiffness of the bridge for longitudinal effects was therefore shifted approximately from pier position 4 to pier position 9. A reduced displacement at Auckland due to temperature and creep effects resulted significantly reducing the strength requirements of piers $18-20$.

A further refinement was introduced by tapering the anchor pier. This enabled the longitudinal stiffness of this pier to be maintained while at the same time reducing the moments in the deck due to longitudinal loading.

The haunched spans adjacent to the anchor pier also assist the transfer of stresses to the bridge deck.

To reduce the expected long term distortions in the end piers due to creep and shrinkage of the deck the tops of piers $3,4,16,17,18,19$ \& 20 were displaced towards the ends of the bridge prior to being cast into the deck. This displacement (varying from 20 to $60 \mathrm{~mm})$, which was sufficient to cause cracking in some of the piers represented approximately half the calculated creep and shrinkage displacement of the deck.

It is of interest to note that during recent inspections of the piers approximately eighteen months after the completion of construction, no obvious signs of visible cracking were observed. 


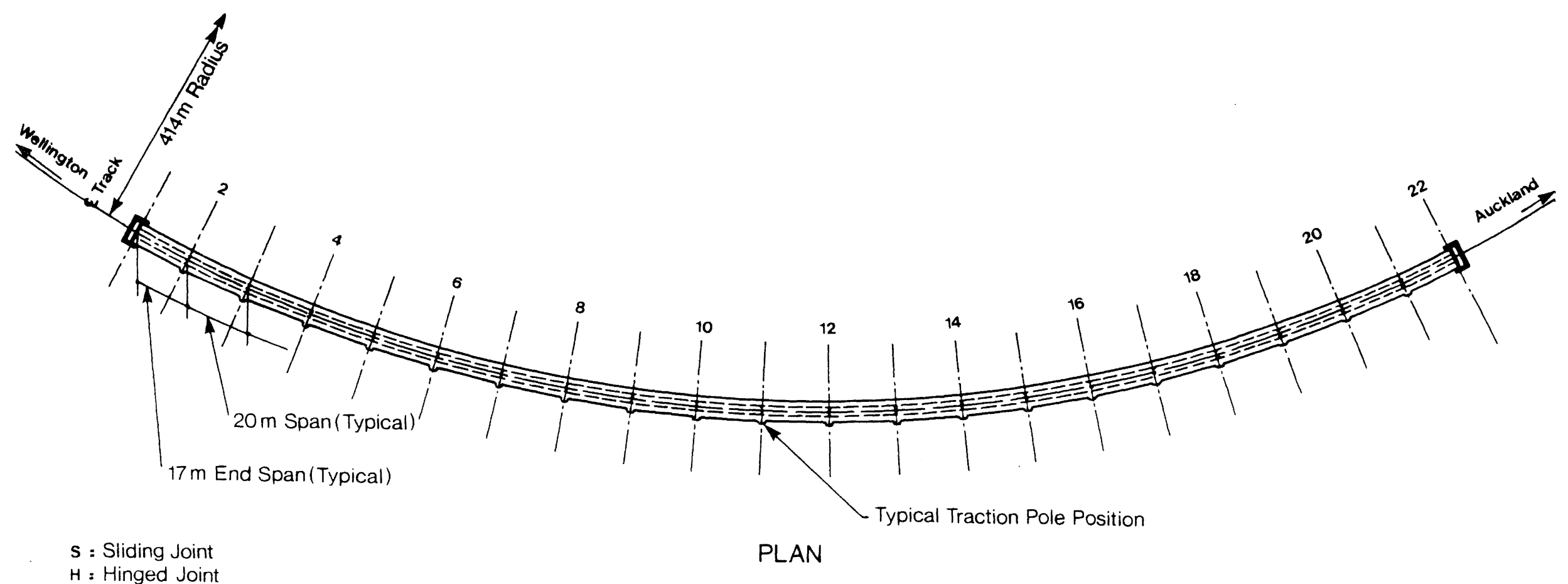

$H$ : Hinged Join

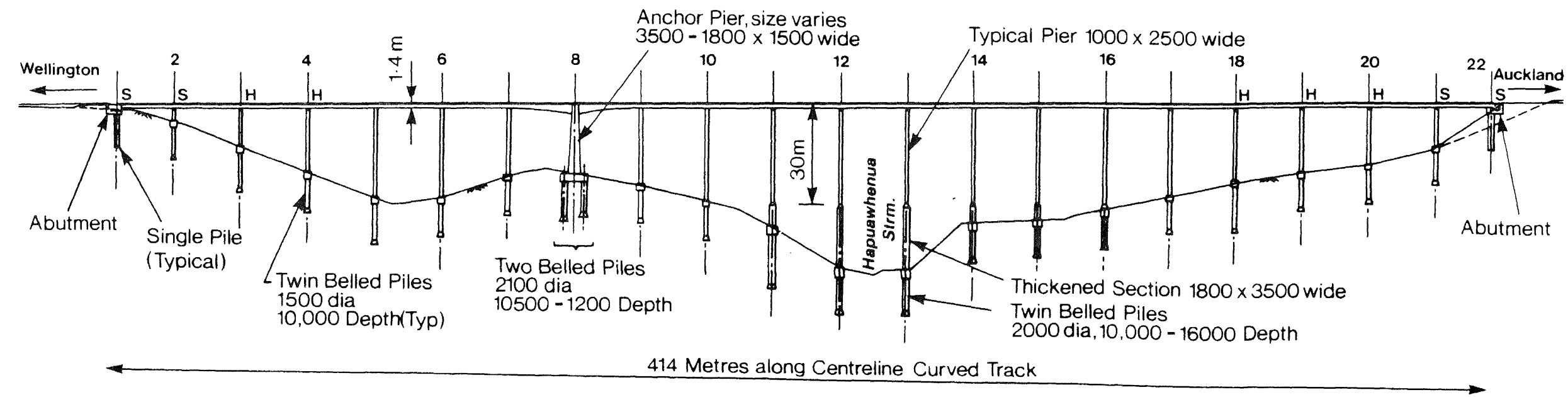

\section{ELEVATION}

FIGURE 1. GENERAL ARRANGEMENT OF THE HAPUAWHENUA RAILWAY BRIDGE. 
Twin bored belled piles into the siltstone and a transverse pile cap support each of the typical piers. The anchor pier is founded on a square pile cap and four bored and belled piles. The abutments are supported on a single pile. Dimensions and arrangement are shown in Fig. 1.

At several pier locations the siltstone surface sloped transversely across the pier and it was necessary to over ream the top of one of the piles in the group to achieve uniform pile stiffness.

\section{DESIGN STANDARDS}

The design loads for the bridge were typically those specified in AREA Manual Chapter 8 (Concrete structures and Foundations) Part 2 [1].

The earthquake load cases were however modified for service load design as:

Dead + Earth Pressure + 0.8 Earthquake

or 0.7 Dead +0.8 Earthquake

for load factor design as:

1.4 (Dead + Earth Pressure) + Earthquake

or 0.9 Dead + Earthquake

and for capacity (Earthquake) design as:

Dead + Earthquake (capacity)

The earthquake loads were derived from NZS 4203 [7] using $C$ for Zone $A, S, M$ and $R=$ 1.0 and $I$ equal to 1.3 to obtain the design spectrum. This is a similar level of load to that which would be specified by the MWD Manual for Highway Bridge Design [5] for a highway bridge of similar importance.

Service load and ultimate strength design of the reinforced and prestressed concrete components were carried out in accordance with the requirements of the AREA Manual. capacity design and detailing of these items was however to the provisions set out in NZS 3101 [6].

The effects of creep \& shrinkage were estimated using the recommendations of references 2 and 3 .

\section{ANALYSIS}

Both three and two dimensional techniques were employed in the analysis of the bridge.

A two dimensional elevational model (based on deck centre line dimensions) was used to determine the actions under the application of the moving live (train) load. In-house plane frame analysis software enabled the evaluation of superstructure bending moment and shear force envelopes resulting from a train wheel load model moving incrementally across the bridge in both directions.

A modal analysis was performed on a three dimensional model of the bridge. Masses up the height of the tallest pier (13) were included to ensure that the seismic response of this slender member was adequately accounted for. Mode shapes were determined and a response spectrum analysis carried out using the code spectrum discussed above. Final scaling of the member actions was carried out manually to ensure the total base shear was at least that required by the code [7]. The analysis indicated that the natural periods of vibration were 1.8 sec. transversely and 1.2 sec. longitudinally. The maximum displacements predicted for the code earthquake loadings were:

Transversely: $125 \mathrm{~mm}$ at pier location 13

and Longitudinally: $40 \mathrm{~mm}$

These displacements were calculated assuming $75 \%$ of gross pier stiffness to allow for cracking.

The three dimensional model was also used to determine the member actions resulting from dead load, centrifugal effects (assuming a train speed of approximately 70 $\mathrm{km} / \mathrm{hr}$ ), wind load on the structure, wind load on the design train, train braking load (assuming a train completely covering the bridge), thermal effects, elastic shortening and creep and shrinkage (approximately as an equivalent temperature decrease).

Under uniform transverse loading the deck was found to be spanning between the stiffer piers at approximately pier locations 3,8 and 19

The tall piers were subjected to a second order structural analysis and were shown to have an adequate factor of safety against instability even when subjected to large induced top displacements, and lateral loads acting on the pier itself.

The piles were analysed for forces consistent with the application of capacity actions in the piers and on the steeper slopes the resistance to sliding of the surface soils provided by the pile cap was also considered.

\section{SPECIAI DETAIITNG}

There are several details in the bridge which were specially devised to ensure adequate performance both during severe earthquake shaking and service load conditions.

At the abutments (refer Fig. 3) the superstructure is free to slide longitudinally on Repco Glacier PTFE/stainless steel pot bearings. Transverse restraint is provided by concrete buffers bearing against the bottom edge of the deck. Vertical restraint is provided by two Macalloy bar tie-downs which pass through vertical ducts in the deck and abutment slab. The duct in the abutment slab is tapered and a rubber pad provided under the Macalloy bar fixing to allow approximately $500 \mathrm{~mm}$ differential longitudinal movement between the deck and abutment before the Macalloy bar is tensioned. 


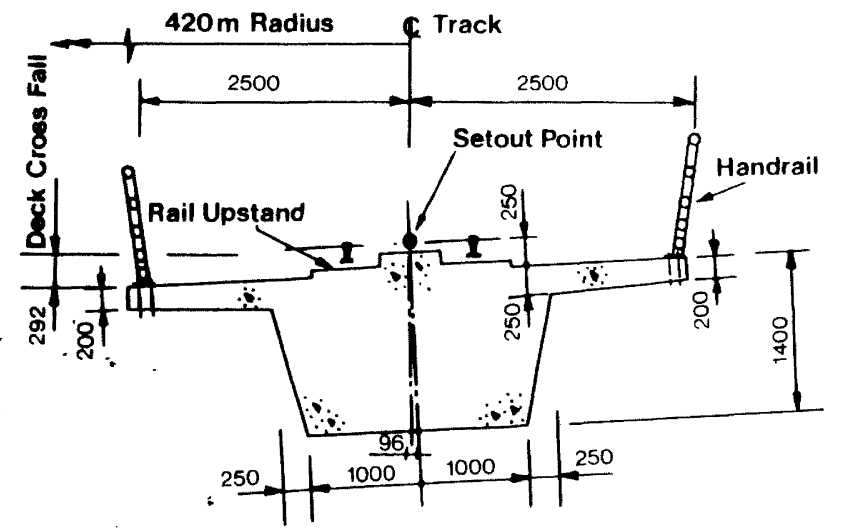

FIGURE 2A. TYPICAL DECK SECTION.

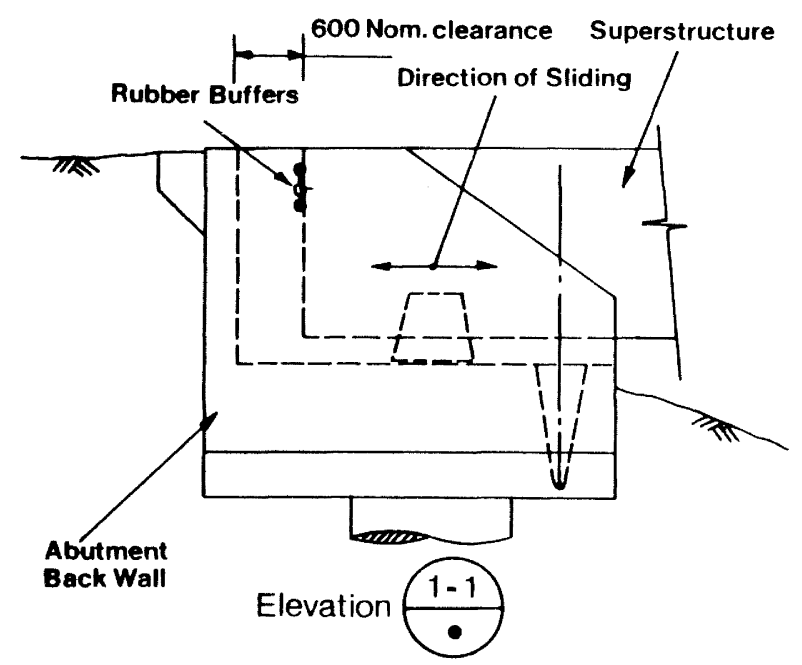

FIGURE 3. TYPICAL ABUTMENT ARRANGEMENT.

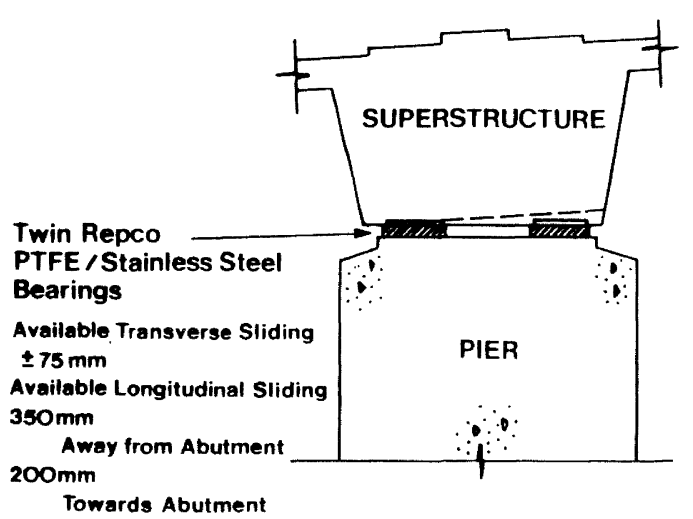

FIGURE 4. TYPICAL PIER/DECK SLIDING JOINT DETAIL ON TOP OF PIERS $2,21$.

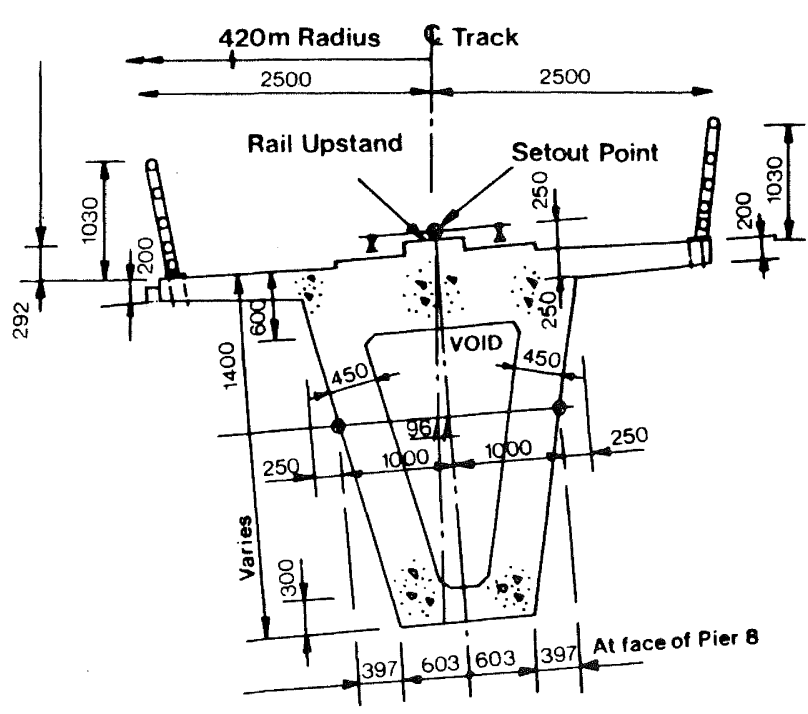

FIGURE 2B. HAUNCED DECK BEAM SECTION BETWEEN PIERS 7 TO 8 AND 8 TO 9
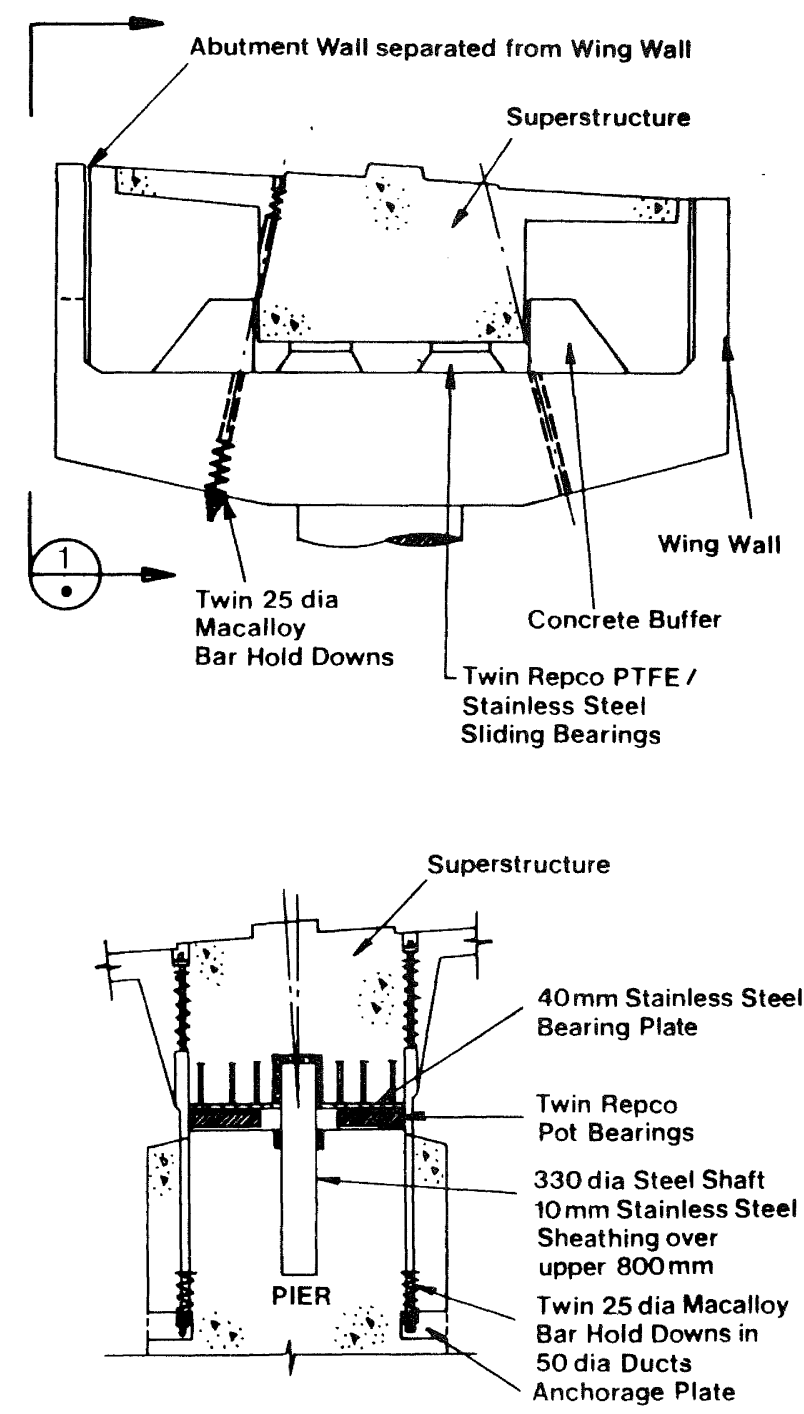

FIGURE 5. TYPICAL PIER/DECK HINGE DETAII ON TOP OF PIERS $3,4,12,18$, AND 20. 
A nominal clearance of $600 \mathrm{~mm}$ has been provided between the deck and the back wall of each abutment. In the event that this proves to be inadequate in a severe earthquake the back wall of the abutment has also been separated from the wing walls and rubber buffers provided to minimise the forces resulting from impact.

A $75 \mathrm{~mm}$ thick steel plate spans between the bridge superstructure and the abutment back wall to support the rails. The plate is tied to the deck and is free to slide on the abutment. Each rail is provided with a specially detailed expansion joint.

Repco multidirectional sliding bearings are located between the deck and piers 2 and 21 to provide a fully sliding condition, (Fig. 4). The available movements in the bearing sliding surfaces are $75 \mathrm{~mm}$ each way transversely and $350 \mathrm{~mm}$ and $200 \mathrm{~mm}$ longitudinally, away and towards the abutment respectively. In addition, the upper bearing plate is recessed flush with the deck soffit to ensure that vertical support is not lost if these displacements are exceeded.

Fig. 5 indicates the detailing provided for the linkage between the deck and top of piers 3, 4, 18, 19 and 20. The superstructure is supported vertically on pairs of Repco pot bearings. Horizontal restraint is provided by a stainless steel sheathed mild steel dowel of $330 \mathrm{~mm}$ diameter cast into the top of the pier. This dowel contacts with a stainless steel plate anchored to the soffit of the superstructure. Two vertical Macalloy bars provide vertical restraint.

Potential plastic hinge regions were detailed in accordance with the provisions of NZS 3101. Hinge regions so detailed included the top and bottom of the anchor pier, the top and bottom of the smaller section portion of the typical piers, the base of the cantilever piers and the upper region of all piles.

\section{PROJECTED SEISMIC PERFORMANCE}

The likely return period of reaching given levels of peak structural response in the bridge have been estimated using procedures described in reference 4 . The performance of the structure beyond first yield discussed below has been estimated assuming equal displacement theories are applicable. That is, if the structure were provided with unlimited strength then the maximum displacement observed in a large earthquake would be approximately the same as for the real structure. This has been found to be generally applicable for long period structures.

It is more convenient to consider each of the principle directions separately, however it is important to recognise that the principle response could be in any direction for any one earthquake. However, it is unlikely that a single earthquake will produce a maximum level of response both transversely and longitudinally. This is of particular relevance when considering large levels of response which have a low risk of occurrence during the expected life

\section{of the bridge.}

In the transverse direction the code earthquake level determined as outlined above is estimated to have a return period of approximately 25 years. If it is assumed that the actual minimum transverse strength of the bridge as a whole is increased beyond that theoretically calculated by a factor of say 1.3 (i.e. due to increased material strengths etc.) then the return period for first yield in the structure is estimated as being in the region of 40 years. The majority of the piers were however proportioned either with minimum flexural reinforcement or for load causes other than transverse earthquake. The estimated response to cause transverse yield in a significant number of piers as detailed is $0.2 \mathrm{~g}$ which has been estimated to have a return period in excess of 100 years.

At a response of approximately $0.5 \mathrm{~g}$ (equivalent to a displacement ductility demand of 2.5 in the piers), it is estimated that the ultimate transverse capacity of the deck will be exceeded. This is considered acceptable for the following reasons:

1. transversely the deck is found to 'fail' in a tension mode with the reinforcement yielding indicating ductile capability.

2 . one perimeter hoop in the deck has been found to be sufficient to allow a significant increase in the ultimate concrete strain.

3. yielding in the deck occurs in a region of low transverse shear and will therefore be spread over a reasonable length keeping ductile curvatures low; and

4. the return period of this level of response is estimated to be in excess of 1000 years.

If the earthquake was large enough it is conceivable that a compression failure could occur in the walkway flanges. Such a response must be considered extremely unlikely in the life of this bridge.

The resulting damage once the ultimate capacity of the deck has been reached is expected to be slight. cracks which have opened on the tension face will partially close requiring some grouting to return the structure to its originally appearance. The prestressing reinforcement will have undergone some yielding and therefore some prestressing force will have been lost. Additional space ducts have been placed in the deck as a contingency and it is expected that these should be sufficient to allow the lost stressing force to be replaced.

Longitudinal yielding at the top of the anchor pier is expected under a longitudinal response of approximately $0.15 \mathrm{~g}$ which has an estimated return period of 25 years. Over-strength in the "hinge' is expected for a response with approximately a 50 year return period, although the response to cause full 
ductility has an estimated return period in the order of 1000 years.

At the 1000 year return period response level (estimated as $0.45 \mathrm{~g}$ ) 'hinging' is expected, top or bottom in at least $80 \%$ of the piers. The analyses performed indicate that some of the hinging will be in the transverse direction due to the curve in plan of the superstructure.

Yielding of the deck is not expected under a longitudinal response as it has been proportioned using capacity design methods to have an ultimate moment capacity greater than the moment input at the top of the piers.

Under a severe response predominantly in the longitudinal direction damage is therefore expected to be restricted to the 'hinge' regions of the piers which have been specially detailed to allow significant ductile yielding to take place.

\section{IN CONCLUSION}

This paper has set out the basis for the design of the replacement Hapuawhenua Railway Bridge and in particular the manner in which the bridge has been designed to resist seismic forces. The designers believe that the structural arrangement chosen has led to the expectation of excellent seismic behaviour while at the same time proving to be an economic solution.

\section{REFERENCES}

1. American Railway Engineering Association. 1981 Manual of Railway Engineering. Chapter 8 Concrete Structures and Foundations. Part 2 Reinforced Concrete Design.

2. Bryant A.H., Wood J.A, Fenwick R.C. 1984. "Creep and Shrinkage in concrete Bridges". RRU Bulletin 70 .

3. Federation Internationale de la Precontrainte. 1970 International Recomnendation for the Design and Construction of concrete structures. CEB-FIP.

4. Jury, R.D. and Hollings, J.P. 1983. "A Seismic Zoning scheme for New Zealand including Lateral Load Deviation". Proc Third South Pacific Conference for Earthquake Engineering.

5. Ministry of Works and Development. 1978. "Manual for Highway Bridge Design" CDP 701/D. Wellington.

6. Standards Association of New Zealand. 1982. "Code of practice for The Design of concrete structures". NZS 3101. wellington.

7. Standards Association of New Zealand 1984. "Code of practice for General Structural Design and Design Loadings for Buildings". NZS 4203. Wellington. 